“ (C) 2018 IEEE. Personal use of this material is permitted. Permission from IEEE must be obtained for all other uses, in any current or future media, including

reprinting/republishing this material for advertising or promotional purposes, creating new collective works, for resale or redistribution to servers or lists, or reuse of any copyrighted component of this work in other works." 


\title{
SaaS E-Commerce Platforms Web Accessibility Evaluation
}

\author{
Osama Sohaib $^{1}$, Mohsen Naderpour ${ }^{1,2}$, Walayat Hussain ${ }^{1}$ \\ ${ }^{1}$ School of Systems, Management and Leadership \\ ${ }^{2}$ Centre for Artificial Intelligence \\ Faculty of Engineering and IT \\ University of Technology Sydney (UTS) \\ Ultimo, NSW 2007, Australia \\ \{Osama.Sohaib, Mohsen.Naderpour, Walayat.Hussain\}@uts.edu.au
}

\begin{abstract}
Web accessibility related to cloud computing is more concerned at the application level where a human interacts with an application via a user interface. Although previous research has identified web accessibility influences on website effectiveness, the evaluation of the relative importance of web accessibility on software-as-a-service (SaaS) e-commerce platform has not been empirically determined. This study evaluates the web accessibility of SaaS e-commerce platform websites. The web accessibility features from the cloud accessibility taxonomy framework were evaluated for people with disabilities such as sensory (hearing and vision), motor (limited use of hands) and cognitive (language and learning disabilities) impairments. We conducted an expert evaluation using Fuzzy TOPSIS (Technique for Order of Preference by Similarity to Ideal Solution). The results show Shopify cloud-based e-commerce platform has a high number of web accessibility features from the proposed cloud accessibility framework followed by 3dCart, BigCommerce, Volusion, and WooCommerce.
\end{abstract}

Keywords-E-commerce, Ecommerce, Cloud computing, Cloud accessibility, People with disabilities, Software-as-a-service, SaaS, Web accessibility, user interface

\section{INTRODUCTION}

Cloud computing has brought a dramatic shift in the IT industry and has changed the way in which organizations plan their IT infrastructure due to its on-demand, highly scalable and affordable service offerings [1]. Cloud computing allows businesses to utilize computing resources from external service providers over the Internet rather than investing in their own IT infrastructure [2].

Cloud service models as per NIST (National Institute of Standards and Technology) [3] are IaaS (infrastructure as a service), PaaS (platform as a service), and SaaS (software as a service) describe how cloud services are made available to the clients. For instance, an e-commerce firm can use an IaaS model to purchase servers, storage, network and operating systems, etc. PaaS provides a pre-built application platform to the client; business requisition resources as they need them, rather than investing in underlying infrastructure for their applications. Alternatively, businesses can quickly launch e-commerce websites without worrying about server configurations and software updates. With the rapid advance and the widespread use of cloud services, Software-as-a-Service (SaaS) has become a good fit for the majority of online businesses. SaaS platforms offer the ease of creating a website, featuring excellent scalability. Concerning the e-commerce, SaaS platforms allow businesses to develop their online store using readily available tools and easy to use drag and drop interfaces $[1,2]$.

Although cloud computing has changed the e-commerce industry, however, its unique web accessibility implications are often minimal [4]. Web accessibility is more concerned with the web user interface than the platform or infrastructure-as-aservice. Researchers have measure customer satisfaction, service quality and the user acceptance of SaaS [5-8]. However, in recent years, there is a growing concern regarding the web accessibility of cloud computing, in particular for people with disabilities [9-11]. SaaS helped to minimize costs and maximize customer satisfaction levels but neglected the accessibility of the e-commerce websites [12]. Businesses ignore the importance of web accessibility and in turn lose out on a large number of consumers who find it difficult to interact with their website [13].

Therefore, the purpose of this study is to evaluate the web accessibility of SaaS e-commerce websites. Following the main objective, the research question is: what is the impact of web accessibility of e-commerce SaaS websites? This study applied Bohn and Tobias [4] cloud accessibility framework to evaluate web accessibility of cloud-based e-commerce platforms websites using Fuzzy TOPSIS (Technique for Order of Preference by Similarity to Ideal Solution), a popular multicriteria decision making (MCDM) technique. The decisionmaker as end-user evaluates the web accessibility features from the cloud accessibility taxonomy framework [4] for people with disabilities.

The study is organized as follows: Section II provides the background information about SaaS and e-commerce, web accessibility and cloud computing. Then it presents the cloud accessibility framework along with a MCDM approach. The research method is explained in Section III followed by case study results in Section IV. Finally, the study concludes in Section V. 


\section{Accepted Manuscript: 2018 IEEE International Conference on Fuzzy Systems (FUZZ-IEEE 2018)}

\section{BACKGROUND AND LITERATURE REVIEW}

This section discusses some background information and related studies about cloud and the e-commerce, cloud web accessibility, and MCDM.

\section{A. Cloud (SaaS) and the e-commerce}

Software-as-a-Service (SaaS) also referred to as on-demand software, the provider hosts the software and provides access to the clients through leasing. SaaS is the best cloud service model to achieve full-service e-commerce, in particular for small-tomedium-sized enterprise [14]. Cloud elastic computing allows services to scale up and scale down on demand, depending on the volume of user traffic to an e-commerce application. The rapid advancement of cloud computing emerged in multi-tenant e-commerce. "Multi-tenancy is a business strategy in which a single instance of a software application serves multiple customers (tenants)." [15]. The multi-tenant SaaS model allows a single application instance to be used by multiple customers thus allowing service providers to support multiple B2C websites from a single software stack and database [15]. SaaS providers can also offer new features and carry out application updates on a single software stack instead of maintaining individual application instances for each tenant [8].

Due to a wide range of cloud services such as - on demand service access, lower expanses both in terms of maintenance and management, higher efficiency and many other valuable features, the e-commerce companies are able to expand their businesses without worrying of the upfront costs, scalability, maintainability and elasticity. While using SaaS, the ecommerce companies could earn a higher return on investment, greater flexibility, higher customer satisfaction by allowing them to select the provider according to their personalized choices [16].

However, for forming a long-term trusted relationship between the e-commerce service provider and a customer they should form a viable service level agreement (SLA) [17-19]. The compliance with SLA between both parties may be determined by gathering data for each HTTP/ HTTPS request and response send to the e-commerce service provider [20]. Tang et al. [21] proposed a trustworthiness cloud service discovery framework to rank cloud services by combining customer feedback rating with the quality of service (QoS) data to assist the customer to choose appropriate cloud service provider. Sohaib and Naderpour [22] highlighted that SaaS is the optimal choice for the e-commerce business.

\section{B. Web Accessibility and Cloud Computing}

The Web Accessibility Initiative (WAI), a working group of World Wide Web Consortium (W3C) deals with the web accessibility and significantly involved in the development of web content accessibility guideline (WCAG). The WAI define web accessibility as: "people with disabilities and older people can perceive, understand, navigate, and interact with the Web, and that they can contribute to the Web [23]. The WCAG version 2.0 is the latest version, which has four principles (perceivable, operable, understandable and robust). These principles are further subdivided into 12 guidelines. For each guideline, testable success criteria are provided and for each of the success criteria, 3 levels (Level A, AA and AAA) are defined [24]. Sohaib and Kang [25-26] highlighted web accessibility in e-commerce for people with disabilities. However, according to [13] web accessibility should not only be addressed to a certain group of people involving disabilities but there should be one and equal access to all people.

Web accessibility related to cloud computing is more concerned at the application level where a human interacts with an application via a user interface [4]. Thus, many of the current web accessibility standards for software/web applications are also applicable to cloud computing applications such as SaaS websites. The most relevant are ISO 9241-151, ISO 924120:2008, Section 508 of the US rehabilitation Act and the WCAG 2.0 [4]. However, cloud computing also offers new cloud based accessibility opportunities such as Global Public Inclusive Infrastructure (GPII) and the Accessibility Application Programming Interfaces (AAPIs) [4].

A number of researchers have evaluated website accessibility for people with disabilities. [25, 26]. Mulfar et al. [11] provided adaptive SaaS user interfaces via virtual machine for people with disabilities in order to enable them accessing assistive technology tools.

However, the Cloud Computing and Accessibility Public Working Group (CCA-PWG) identified a few issues that are unique to managing accessibility in the cloud [4]. These issues include software version control, reliance on the browser, platform quandary, the user of thin clients and rich data visualizations. Users with disabilities such as sensory (hearing and vision), motor (limited use of hands) and cognition (language and learning) have a process and technological barriers accessing electronic information. For example:

\section{Audio and alternatives.}

A deaf user or who have difficulty in the hearing will need text captioning for all audio content [19]. Sign language could also be a more effective form of communication [4].

\section{Control, Input and Operation.}

A user with motor impairments will have difficulty using a mouse or keyboard. For-example, interacting with product images as three-dimensional (3D) virtual models, $360^{\circ}$ rotation view, which allows the manipulation of product images [19]. Such users may need an alternative input devices or speech recognition system [4].

Reading, understanding, learning and managing.

A user with cognitive disabilities (reading, thinking, remembering, navigating etc.) will find difficult to process information on a webpage [19].

Speaking and communicating.

A user with speech disabilities produces speech that is not recognizable by other people. Such users find it difficult to interact with the website, if the website services only offer a phone number as its contact information.

Visual. 


\section{Accepted Manuscript: 2018 IEEE International Conference on Fuzzy Systems (FUZZ-IEEE 2018)}

Users with low vision, blindness and color-blindness struggle with many websites. Images without a text alternative, lack of sensitivity to certain colors can be a huge barrier for those people with visual disabilities. Such users may require usage of screen readers, magnification and high contrast web design [19].

\section{Cloud Accessibility}

As discussed above, it is important to have a consistent taxonomical framework of cloud accessibility to create information resources that make sense to the users, in particular for people with disabilities. Bohn and Tobias [4] explained a series of use cases of how a user with disabilities interacts in different circumstances, which are useful in considering accessibility in cloud computing. Figure 1 shows the Cloud Accessibility taxonomy framework [4].

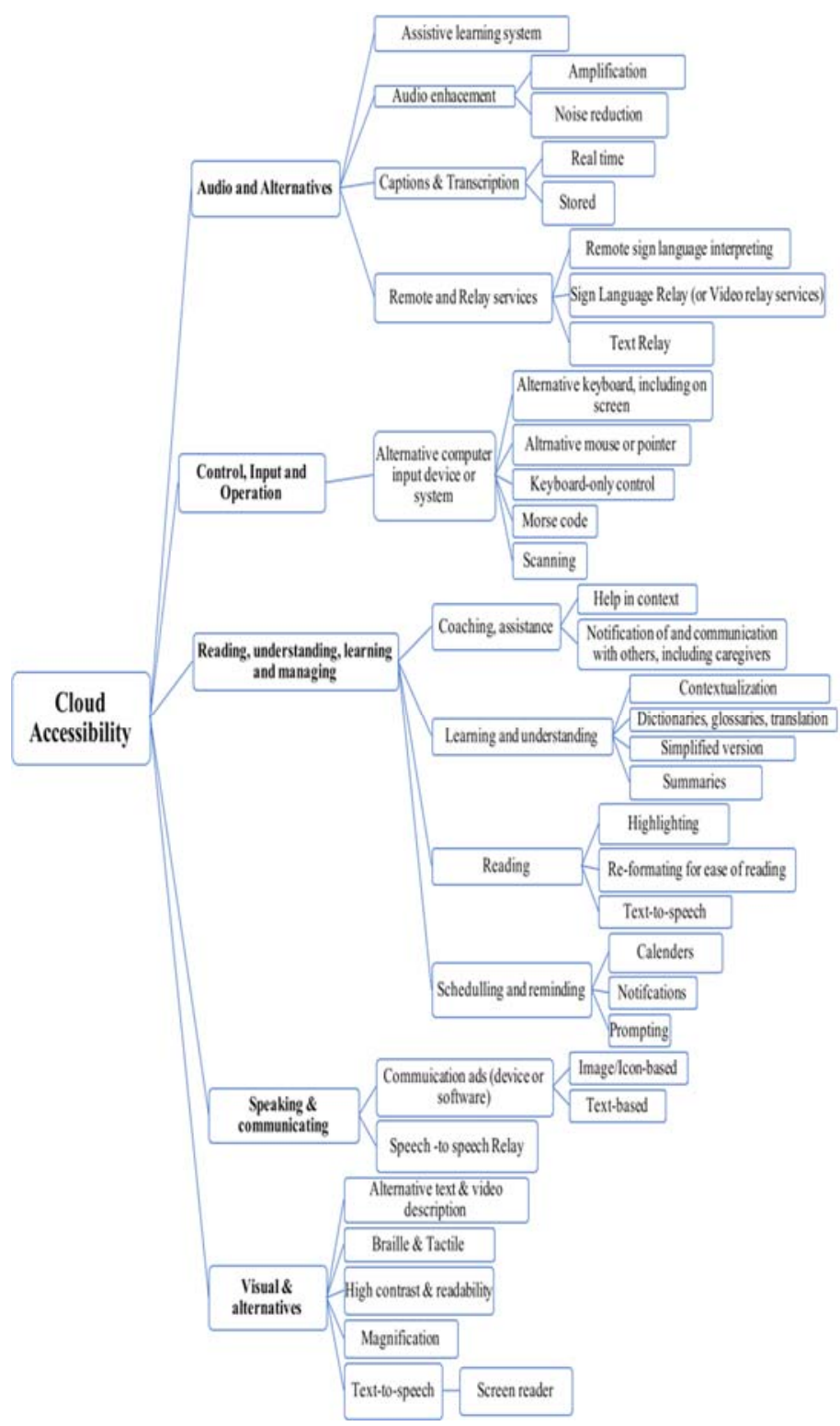

Fig 1: Cloud Accessibility [4].
Multi-criteria decision-making refers to the decision making in the existence of multiple and conflicting criteria [2728]. MCDM involves both quantitative and qualitative factors and there are numerous MCDM techniques for choosing the best feasible option. Due to fuzziness in criteria and decision makers' judgments, many real-world decision problems denote fuzzy multi-criteria decision making [31]. This paper uses the fuzzy technique for order preference by similarity to ideal solution (TOPSIS) [22] to deal with the decision-making problem. TOPSIS has been firstly developed by Hwang and Yoon [29] and has been an acceptable method in different application areas [30].

A typical MCDM problem based on $m$ alternatives $\left(A_{1}, A_{2}, \ldots, A_{m}\right)$ and $n$ criteria $\left(C_{1}, C_{2}, \ldots, C_{n}\right)$ is presented as:

$$
X=\left[x_{i j}\right]_{m * n}, W=\left[w_{j}\right]_{n}
$$

where $X$ is the decision matrix, $x_{i j}$ is the performance of the $i$ th alternative with respect to the $j$ th criterion, $W$ is the weight vector, and $w_{j}$ is the weight of the $j$ th criterion.

In fuzzy MCDM both $X$ and $W$ can be linguistic terms that are presented by fuzzy numbers and defining appropriate membership functions. Such functions can be determined in different ways, this paper assumes that parametric triangular ones are good enough to capture the vagueness of those linguistic assessments.

Assume, $\tilde{X}=\left\{\tilde{x}_{i j}, i=1,2, \ldots, m, j=1, \ldots, n\right\}$ is the linguistic decision matrix for alternatives with respect to criteria, and $\widetilde{W}=\left\{\widetilde{w}_{j}, j=1, \ldots, n\right\}$ is the linguistic vector of criteria weights.

The fuzzy TOPSIS method is as follows:

Step 1: Normalized fuzzy decision matrix: The fuzzy linguistic rating $\tilde{x}_{i j}$ preserves the property that the ranges of normalized triangular fuzzy numbers belong to $[0,1]$; thus, there is no need for normalization.

Step 2: Weighted normalized fuzzy decision matrix: Considering the different importance values of each criterion, the weighted normalized fuzzy decision matrix is constructed as:

$$
\tilde{V}=\left[\tilde{v}_{i j}\right]_{m * n} i=1, \ldots, m, j=1,2, \ldots, n
$$

where $\tilde{v}_{i j}=\tilde{x}_{i j} \otimes \widetilde{w}_{j}$ is the standard multiplication of two triangular fuzzy numbers. Assume $\tilde{a}=\left(a_{1}, b_{1}, c_{1}\right)$ and $\tilde{b}=$ $\left(a_{2}, b_{2}, c_{2}\right)$, then

$$
\tilde{a} \otimes \tilde{b}=\left(a_{1} a_{2}, b_{1} b_{2}, c_{1} c_{2}\right)
$$

Step 3: Identification of fuzzy positive ideal (FPI) and fuzzy negative ideal (FNI) solutions: The FPI and FNI solutions are determined as follows:

$$
\begin{gathered}
A^{+}=\left\{\widetilde{v}_{1}{ }^{+}, \widetilde{v}_{2}{ }^{+}, \ldots, \widetilde{v}_{n}{ }^{+}\right\}= \\
\left\{\left(\max _{j} \tilde{v}_{i j} \mid i \in I^{\prime}\right) \text { or }\left(\min _{j} \tilde{v}_{i j} \mid i \in I^{\prime \prime}\right)\right\} i=1, \ldots, m j=1, \ldots, n \\
A^{-}=\left\{\widetilde{v}_{1}{ }^{-}, \widetilde{v}_{2}{ }^{-}, \ldots, \widetilde{v}_{n}{ }^{-}\right\}= \\
\left\{\left(\min _{j} \tilde{v}_{i j} \mid i \in I^{\prime}\right) \operatorname{or}\left(\max _{j} \tilde{v}_{i j} \mid i \in I^{\prime \prime}\right)\right\} i=1, \ldots, m j=1, \ldots, n
\end{gathered}
$$

\section{Multi-Criteria Decision Making}




\section{Accepted Manuscript: 2018 IEEE International Conference on Fuzzy Systems (FUZZ-IEEE 2018)}

where $I^{\prime}$ is associated with benefit criteria and $I^{\prime \prime}$ is associated with cost criteria.

Step 4: Calculation of distances: The distance of each alternative from FPI and FNI is calculated as follows:

$$
\begin{gathered}
D_{j}^{+}=\sum_{j=1}^{n} d\left(\tilde{v}_{i j}, \widetilde{v}_{l}^{+}\right) \quad j=1,2, \ldots, n \\
D_{j}^{-}=\sum_{j=1}^{n} d\left(\tilde{v}_{i j}, \widetilde{v}_{l}^{-}\right) \quad j=1,2, \ldots, n
\end{gathered}
$$

where $d(\tilde{a}, \tilde{b})$ is the vertex method that calculates the distance between two triangular fuzzy numbers $\tilde{a}$ and $\tilde{b}$ :

$d(\tilde{a}, \tilde{b})=\sqrt{\frac{1}{3}\left[\left(a_{1}-a_{2}\right)^{2}+\left(b_{1}-b_{2}\right)^{2}+\left(c_{1}-c_{2}\right)^{2}\right]}$

Step 5: Calculation of similarities: The similarities to FPI solution is measured as follows:

$$
C_{j}=\frac{D_{j}^{-}}{D_{j}^{+}+D_{j}^{-}} \quad j=1,2, \ldots, n
$$

Step 6: Ranking of alternatives: The alternatives are ordered based on $C_{j}$ in descending. The alternative with highest $C_{j}$ is the best choice.

\section{METHODOLOGY}

Fig. 2 represents the proposed methodology for the decision-making problem. As can be seen, it consists of four steps that are explained in the following sub-sections.

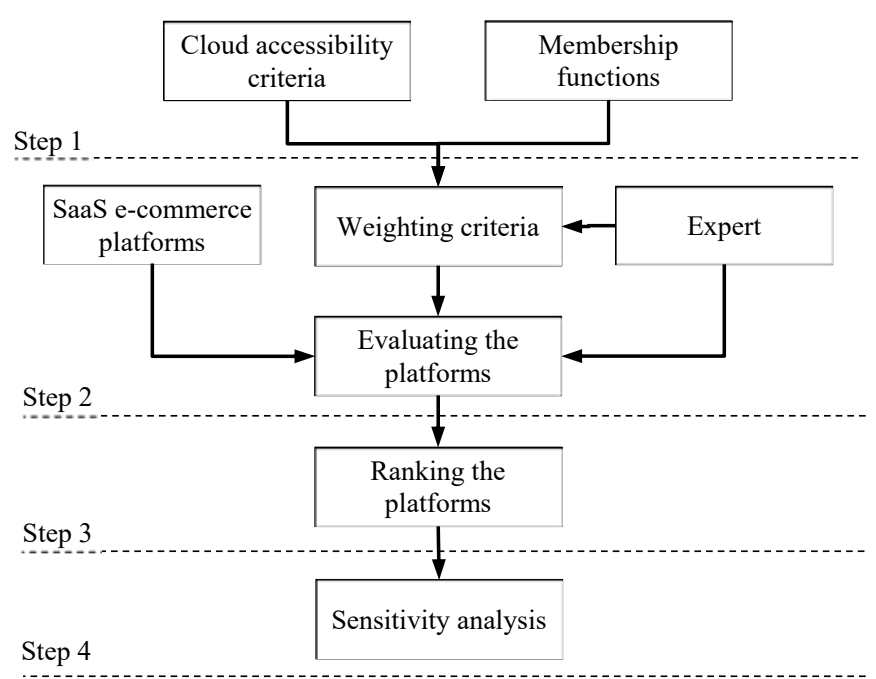

Fig 2. The proposed methodology.

\section{A. Step 1}

The cloud accessibility criteria are determined based on Bohn and Tobias [4] as explained in Section II.C. The paper uses triangular fuzzy numbers to express the importance of each criteria. Triangular fuzzy numbers make the computations easy and they have shown their effectiveness in formulating decision problems where the information available is subjective and imprecise. The linguistic variables proposed by [31] as represented in Table I are used for weighting criteria.

TABLE I. FUZZY LINGUISTIC TERMS AND FUZZY NUMBERS FOR WEIGHTING CRITERIA

\begin{tabular}{|l|l|}
\hline Linguistic term & Fuzzy number \\
\hline Very low (VL) & $(0,0,0.2)$ \\
\hline Low (L) & $(0.05,0.2,0.35)$ \\
\hline Medium low (ML) & $(0.2,0.35,0.5)$ \\
\hline Medium (M) & $(0.35,0.5,0.65)$ \\
\hline Medium high (MH) & $(0.5,0.65,0.8)$ \\
\hline High $(\mathrm{H})$ & $(0.65,0.8,0.95)$ \\
\hline Very high $(\mathrm{VH})$ & $(0.8,1,1)$ \\
\hline
\end{tabular}

Likewise, triangular fuzzy numbers are used to express evaluation of each alternative. Table II illustrates each fuzzy linguistic term to its correspondent fuzzy numbers.

TABLE II. FUZZY LINGUISTIC TERMS AND FUZZY NUMBERS FOR EVALUATING ALTERNATIVES

\begin{tabular}{|l|l|}
\hline Linguistic term & Fuzzy number \\
\hline Not exist (NE) & $(0,0,0)$ \\
\hline Very poor (VP) & $(0,0,0.1)$ \\
\hline Poor (P) & $(0.05,0.2,0.3)$ \\
\hline Medium poor (MP) & $(0.2,0.3,0.5)$ \\
\hline Fair (F) & $(0.3,0.5,0.6)$ \\
\hline Medium good (MG) & $(0.5,0.6,0.8)$ \\
\hline Good (G) & $(0.6,0.8,1)$ \\
\hline Very good (VG) & $(0.8,1,1)$ \\
\hline
\end{tabular}

\section{B. Step 2}

A list of SaaS e-commerce platforms along with designed linguistic terms for weighting criteria and evaluating alternatives are presented for an expert. The expert is asked to firstly weight criteria and secondly access the platforms for evaluation.

\section{Step 3}

The fuzzy TOPSIS presented in Section II.D is relied upon in this step to rank the alternatives.

\section{Step 4}

If the platforms show close scores, it is required to do a sensitivity analysis. Sensitivity analysis addresses this question that how sensitive is the overall decision of small changes in the individual weights? This question is answered by varying slightly the values obtained during expert elicitation and observing the effects of the decision. This is useful in situations where uncertainties exist in the definition of the importance of different factors [32]. Here, sensitivity analysis is conducted in order to see the importance of criteria weights in selecting the best alternative among the SaaS e-commerce platforms. 


\section{Accepted Manuscript: 2018 IEEE International Conference on Fuzzy Systems (FUZZ-IEEE 2018)}

\section{IV.CASE STUDY}

This study intends to evaluate SaaS e-commerce platform websites for web accessibility based on Bohn and Tobias [4] cloud accessibility taxonomy framework. An expert was invited to survey five alternatives including:

- P1: Shopify

- P2: BigCommerce

- P3: Volusion

- P4: 3dCart

- P5: WooCommerce

These providers are considered as the top SaaS e-commerce platforms. One website from each provider in the electronics category is selected to evaluate the cloud web accessibility. The decision-maker is an expert in web content accessibility guidelines (WCAG). The proposed cloud accessibility evaluation criteria were explained to the expert. The goal was to evaluate the web accessibility features from the cloud accessibility taxonomy framework for people with disabilities.

\section{A. Implementation}

There are 33 criteria as summarized in Table III. The expert assigned a linguistic term to represent the importance of each criteria as shown in the last column of Table III.

TABLE III: CRITERIA AND CORRESPONDING WEIGHTS

\begin{tabular}{|l|c|c|}
\hline Criteria & Symbol & Weight \\
\hline Assistive learning system & $\mathrm{C} 1$ & $\mathrm{MH}$ \\
\hline Audio enhancement: Amplification & $\mathrm{C} 2$ & $\mathrm{~L}$ \\
\hline Audio enhancement: Noise reduction & $\mathrm{C} 3$ & $\mathrm{~L}$ \\
\hline Caption and Transcription: Real-time & $\mathrm{C} 4$ & $\mathrm{H}$ \\
\hline Caption and Transcription: Stored & $\mathrm{C} 5$ & $\mathrm{VH}$ \\
\hline $\begin{array}{l}\text { Remote and Relay Services: Remote sign } \\
\text { language interpreting }\end{array}$ & $\mathrm{C} 6$ & $\mathrm{MH}$ \\
\hline Remote and Relay Services: Sign language relay & $\mathrm{C} 7$ & $\mathrm{MH}$ \\
\hline Remote and Relay Services: Text relay & $\mathrm{C} 8$ & $\mathrm{ML}$ \\
\hline The alternative keyboard on the screen & $\mathrm{C} 9$ & $\mathrm{H}$ \\
\hline Alternative mouse or pointer on the screen & $\mathrm{C} 10$ & $\mathrm{H}$ \\
\hline Keyboard only control & $\mathrm{C} 11$ & $\mathrm{M}$ \\
\hline Morse code & $\mathrm{C} 12$ & $\mathrm{M}$ \\
\hline Scanning & $\mathrm{C} 13$ & $\mathrm{M}$ \\
\hline Coaching assistance: Help in context & $\mathrm{C} 14$ & $\mathrm{H}$ \\
\hline $\begin{array}{l}\text { Coaching assistance: Notification of and } \\
\text { communication with others }\end{array}$ & $\mathrm{C} 15$ & $\mathrm{H}$ \\
\hline Learning and understanding: Contextualization & $\mathrm{C} 16$ & $\mathrm{H}$ \\
\hline $\begin{array}{l}\text { Learning and understanding: Dictionaries, } \\
\text { glossary, translation }\end{array}$ & $\mathrm{C} 17$ & $\mathrm{MH}$ \\
\hline Learning and understanding: Simplified version & $\mathrm{C} 18$ & $\mathrm{MH}$ \\
\hline Learning and understanding: Summaries & $\mathrm{C} 19$ & $\mathrm{M}$ \\
\hline Reading: Highlighting & $\mathrm{C} 20$ & $\mathrm{H}$ \\
\hline Reading: Re-formatting for ease of reading & $\mathrm{C} 21$ & $\mathrm{M}$ \\
\hline Reading: Text-to speech & $\mathrm{C} 22$ & $\mathrm{MH}$ \\
\hline Scheduling and reminding: Calendars & $\mathrm{C} 23$ & $\mathrm{M}$ \\
\hline Scheduling and reminding: Notification & $\mathrm{C} 24$ & $\mathrm{M}$ \\
\hline Scheduling and reminding: Prompting & $\mathrm{C} 25$ & $\mathrm{~L}$ \\
\hline $\begin{array}{l}\text { Communication device/software: Image or icon } \\
\text { based }\end{array}$ & $\mathrm{C} 26$ & $\mathrm{VH}$ \\
\hline Communication device/software: Text-based & $\mathrm{C} 27$ & $\mathrm{VH}$ \\
\hline
\end{tabular}

\begin{tabular}{|l|c|c|}
\hline Speech-to-speech relay & $\mathrm{C} 28$ & $\mathrm{MH}$ \\
\hline $\begin{array}{l}\text { Visual \& alternatives: Alternative text and video } \\
\text { description }\end{array}$ & $\mathrm{C} 29$ & $\mathrm{VH}$ \\
\hline Visual \& alternatives: Braille and tactile & $\mathrm{C} 30$ & $\mathrm{H}$ \\
\hline $\begin{array}{l}\text { Visual \& alternatives: High contrast and } \\
\text { readability }\end{array}$ & $\mathrm{C} 31$ & $\mathrm{VH}$ \\
\hline Visual \& alternatives: Magnification & $\mathrm{C} 32$ & $\mathrm{VH}$ \\
\hline Text-to speech screen reader & $\mathrm{C} 33$ & $\mathrm{VH}$ \\
\hline
\end{tabular}

The expert then evaluated the alternatives against each criterion. The fuzzy decision matrix is shown in Table IV.

TABLE IV: FUZZY DECISION MATRIX

\begin{tabular}{|c|c|c|c|c|c|}
\hline Criteria & P1 & P2 & P3 & P4 & P5 \\
\hline C1 & $\mathrm{G}$ & VP & VP & $\mathrm{F}$ & $P$ \\
\hline $\mathrm{C} 2$ & $\mathrm{NE}$ & $\mathrm{NE}$ & $\mathrm{NE}$ & $\mathrm{NE}$ & $\mathrm{NE}$ \\
\hline $\mathrm{C} 3$ & $\mathrm{NE}$ & $\mathrm{NE}$ & $\mathrm{NE}$ & $\mathrm{NE}$ & $\mathrm{NE}$ \\
\hline $\mathrm{C} 4$ & NE & $\mathrm{NE}$ & $\mathrm{NE}$ & $\mathrm{NE}$ & $\mathrm{NE}$ \\
\hline $\mathrm{C} 5$ & $\mathrm{~F}$ & $\mathrm{NE}$ & $\mathrm{NE}$ & $\mathrm{NE}$ & MP \\
\hline C6 & $\mathrm{NE}$ & $\mathrm{NE}$ & $\mathrm{NE}$ & $\mathrm{NE}$ & $\mathrm{NE}$ \\
\hline $\mathrm{C} 7$ & $\mathrm{NE}$ & $\mathrm{NE}$ & $\mathrm{NE}$ & $\mathrm{NE}$ & $\mathrm{NE}$ \\
\hline $\mathrm{C} 8$ & $\mathrm{NE}$ & $\mathrm{NE}$ & $\mathrm{NE}$ & $\mathrm{NE}$ & $\mathrm{NE}$ \\
\hline C9 & $\mathrm{NE}$ & $\mathrm{NE}$ & $\mathrm{NE}$ & $\mathrm{NE}$ & $\mathrm{NE}$ \\
\hline $\mathrm{C} 10$ & $\mathrm{NE}$ & $\mathrm{NE}$ & $\mathrm{NE}$ & $\mathrm{NE}$ & $\mathrm{NE}$ \\
\hline $\mathrm{C} 11$ & $\mathrm{G}$ & MG & MG & $\mathrm{G}$ & $\mathrm{MG}$ \\
\hline $\mathrm{C} 12$ & $\mathrm{NE}$ & $\mathrm{NE}$ & $\mathrm{NE}$ & $\mathrm{NE}$ & $\mathrm{NE}$ \\
\hline $\mathrm{C} 13$ & $\mathrm{NE}$ & $\mathrm{NE}$ & $\mathrm{NE}$ & $\mathrm{NE}$ & $\mathrm{NE}$ \\
\hline C14 & MG & MG & $\mathrm{F}$ & $\mathrm{F}$ & MP \\
\hline $\mathrm{C} 15$ & $\mathrm{~F}$ & MP & $\mathrm{P}$ & $\mathrm{F}$ & $\mathrm{P}$ \\
\hline C16 & $\mathrm{F}$ & MP & $\mathrm{P}$ & $\mathrm{P}$ & $\mathrm{P}$ \\
\hline C17 & $\mathrm{F}$ & MP & $\mathrm{P}$ & $\mathrm{P}$ & $\mathrm{P}$ \\
\hline $\mathrm{C} 18$ & G & MP & $\mathrm{P}$ & $\mathrm{F}$ & MP \\
\hline $\mathrm{C} 19$ & $\mathrm{~F}$ & $\mathrm{P}$ & VP & $\mathrm{P}$ & $\mathrm{P}$ \\
\hline $\mathrm{C} 20$ & MP & MP & $\mathrm{P}$ & MP & $\mathrm{P}$ \\
\hline $\mathrm{C} 21$ & $\mathrm{P}$ & $\mathrm{P}$ & VP & $\mathrm{F}$ & $P$ \\
\hline $\mathrm{C} 22$ & $\mathrm{NE}$ & $\mathrm{NE}$ & $\mathrm{NE}$ & $\mathrm{NE}$ & $\mathrm{NE}$ \\
\hline $\mathrm{C} 23$ & $P$ & $\mathrm{NE}$ & $\mathrm{NE}$ & $\mathrm{NE}$ & $\mathrm{NE}$ \\
\hline $\mathrm{C} 24$ & MP & $\mathrm{P}$ & $\mathrm{P}$ & $\mathrm{F}$ & VP \\
\hline $\mathrm{C} 25$ & $\mathrm{~F}$ & $P$ & $\mathrm{P}$ & $\mathrm{F}$ & $P$ \\
\hline $\mathrm{C} 26$ & VG & $\mathrm{G}$ & $\mathrm{F}$ & G & $P$ \\
\hline $\mathrm{C} 27$ & VG & $\mathrm{G}$ & $\mathrm{F}$ & $\mathrm{G}$ & $\mathrm{P}$ \\
\hline $\mathrm{C} 28$ & $\mathrm{NE}$ & $\mathrm{NE}$ & $\mathrm{NE}$ & $\mathrm{NE}$ & $\mathrm{NE}$ \\
\hline $\mathrm{C} 29$ & VG & $\mathrm{G}$ & MG & VG & MP \\
\hline $\mathrm{C} 30$ & $\mathrm{NE}$ & $\mathrm{NE}$ & $\mathrm{NE}$ & $\mathrm{NE}$ & $\mathrm{NE}$ \\
\hline $\mathrm{C} 31$ & VG & $\mathrm{G}$ & MG & VG & MP \\
\hline $\mathrm{C} 32$ & $\mathrm{VP}$ & $\mathrm{P}$ & MG & $\mathrm{F}$ & VP \\
\hline C33 & $\mathrm{NE}$ & $\mathrm{NE}$ & $\mathrm{NE}$ & $\mathrm{NE}$ & $\mathrm{NE}$ \\
\hline
\end{tabular}

\section{B. Results}

According to Step 3 of the research methodology, fuzzy TOPSIS is applied for ranking of the platforms. Considering that all criteria are benefited, the FPI $\left(A^{+}\right)$and the FNI $\left(A^{-}\right)$ solutions are determined. Fuzzy TOPSIS results are summarized in Table V, and earlier matrices are omitted due to space consideration.

TABLE V: FUZZY TOPSIS RESULTS. 
Accepted Manuscript: 2018 IEEE International Conference on Fuzzy Systems (FUZZ-IEEE 2018)

\begin{tabular}{|l|l|l|l|l|l|}
\hline & $\mathrm{P} 1$ & $\mathrm{P} 2$ & $\mathrm{P} 3$ & $\mathrm{P} 4$ & $\mathrm{P} 5$ \\
\hline$D_{j}^{+}$ & 25.47 & 27.68 & 28.83 & 26.66 & 29.91 \\
\hline$D_{j}^{-}$ & 8.65 & 6.25 & 4.79 & 7.3 & 3.71 \\
\hline$C_{j}$ & 0.25 & 0.18 & 0.14 & 0.21 & 0.11 \\
\hline Rank & 1 & 3 & 4 & 2 & 5 \\
\hline
\end{tabular}

As can be seen, according to $C_{j}, \mathrm{P} 1$ which is Shopify, is considered as the best choice followed by P4, P2, P3, and P5.

\section{Sensitivity Analysis}

In Step 4, the sensitivity analysis is performed to investigate the impact of criteria weights on the decision-making problem. The experiment details are provided in Table VI. In the first seven experiments, the criteria weights are set equal to each linguistic variable, i.e. VL, L, ..., VH. In Experiments 8 to 26, the weight of one criterion is set as $\mathrm{VH}$ one by one and the rest is set to VL. The aim is to see which criteria have the most important influence on the decision-making process. It is worth noting that those criteria that do not exist (i.e. have the linguistic term "NE" in Table IV), do not have any influence on the decision-making process. Hence, they are excluded from the sensitivity analysis.

TABLE VI: SENSITIVITY ANALYSIS EXPERIMENTS.

\begin{tabular}{|c|c|c|c|c|c|c|}
\hline Exp. & & P1 & $\mathrm{P} 2$ & P3 & P4 & P5 \\
\hline E1 & $\mathrm{W}_{\mathrm{C} 1-\mathrm{C} 33}=\mathrm{VL}$ & 0.04 & 0.03 & 0.03 & 0.04 & 0.02 \\
\hline E2 & $\mathrm{W}_{\mathrm{C} 1-\mathrm{C} 33}=\mathrm{L}$ & 0.09 & 0.06 & 0.05 & 0.07 & 0.04 \\
\hline E3 & $\mathrm{W}_{\mathrm{Cl}-\mathrm{C} 33}=\mathrm{ML}$ & 0.13 & 0.09 & 0.07 & 0.11 & 0.06 \\
\hline E4 & $\mathrm{W}_{\mathrm{C} 1-\mathrm{C} 33}=\mathrm{M}$ & 0.18 & 0.13 & 0.1 & 0.15 & 0.08 \\
\hline E5 & $\mathrm{W}_{\mathrm{Cl}-\mathrm{C} 33}=\mathrm{MH}$ & 0.23 & 0.16 & 0.12 & 0.19 & 0.1 \\
\hline E6 & $\mathrm{W}_{\mathrm{Cl}-\mathrm{C} 33}=\mathrm{H}$ & 0.27 & 0.19 & 0.15 & 0.23 & 0.12 \\
\hline E7 & $\mathrm{W}_{\mathrm{C} 1-\mathrm{C} 33}=\mathrm{VH}$ & 0.31 & 0.21 & 0.16 & 0.26 & 0.14 \\
\hline E8 & $\mathrm{W}_{\mathrm{Cl}}=\mathrm{VH}, \mathrm{W}_{\mathrm{C}, \mathrm{i}, \mathrm{i} 1}=\mathrm{VL}$ & 0.06 & 0.03 & 0.03 & 0.05 & 0.03 \\
\hline E9 & $\mathrm{W}_{\mathrm{C} 5}=\mathrm{VH}, \mathrm{W}_{\mathrm{Ci}, \mathrm{i} \neq 5}=\mathrm{VL}$ & 0.06 & 0.03 & 0.03 & 0.04 & 0.03 \\
\hline E10 & $\mathrm{W}_{\mathrm{C} 11}=\mathrm{VH}, \mathrm{W}_{\mathrm{C}, \mathrm{i}, 111}=\mathrm{VL}$ & 0.06 & 0.05 & 0.04 & 0.06 & 0.04 \\
\hline E11 & $\mathrm{W}_{\mathrm{C} 14}=\mathrm{VH}, \mathrm{W}_{\mathrm{Ci}, \mathrm{i} \neq 14}=\mathrm{VL}$ & 0.06 & 0.05 & 0.04 & 0.05 & 0.03 \\
\hline E12 & $\mathrm{W}_{\mathrm{C} 15}=\mathrm{VH}, \mathrm{W}_{\mathrm{C}, \mathrm{i}, 115}=\mathrm{VL}$ & 0.06 & 0.04 & 0.03 & 0.05 & 0.03 \\
\hline E13 & $\mathrm{W}_{\mathrm{C} 16}=\mathrm{VH}, \mathrm{W}_{\mathrm{Ci}, \mathrm{i} \neq 16}=\mathrm{VL}$ & 0.06 & 0.04 & 0.03 & 0.04 & 0.03 \\
\hline E14 & $\mathrm{W}_{\mathrm{C} 17}=\mathrm{VH}, \mathrm{W}_{\mathrm{Ci}, \mathrm{i} \neq 17}=\mathrm{VL}$ & 0.06 & 0.04 & 0.03 & 0.04 & 0.03 \\
\hline E15 & $\mathrm{W}_{\mathrm{C} 18}=\mathrm{VH}, \mathrm{W}_{\mathrm{Ci}, \mathrm{i} \neq 18}=\mathrm{VL}$ & 0.06 & 0.04 & 0.03 & 0.05 & 0.03 \\
\hline E16 & $\mathrm{W}_{\mathrm{C} 19}=\mathrm{VH}, \mathrm{W}_{\mathrm{Ci}, \mathrm{i} \neq 19}=\mathrm{VL}$ & 0.06 & 0.04 & 0.03 & 0.04 & 0.03 \\
\hline E17 & $\mathrm{W}_{\mathrm{C} 20}=\mathrm{VH}, \mathrm{W}_{\mathrm{Ci}, \mathrm{i} \neq 20}=\mathrm{VL}$ & 0.05 & 0.04 & 0.03 & 0.05 & 0.03 \\
\hline E18 & $\mathrm{W}_{\mathrm{C} 21}=\mathrm{VH}, \mathrm{W}_{\mathrm{Ci}, \mathrm{i} \neq 21}=\mathrm{VL}$ & 0.05 & 0.04 & 0.03 & 0.05 & 0.03 \\
\hline E19 & $\mathrm{W}_{\mathrm{C} 23}=\mathrm{VH}, \mathrm{W}_{\mathrm{Ci}, \mathrm{i}+23}=\mathrm{VL}$ & 0.05 & 0.03 & 0.03 & 0.04 & 0.02 \\
\hline E20 & $\mathrm{W}_{\mathrm{C} 24}=\mathrm{VH}, \mathrm{W}_{\mathrm{Ci}, \mathrm{i}+24}=\mathrm{VL}$ & 0.05 & 0.04 & 0.03 & 0.05 & 0.02 \\
\hline E21 & $\mathrm{W}_{\mathrm{C} 25}=\mathrm{VH}, \mathrm{W}_{\mathrm{Ci}, \mathrm{i} i 25}=\mathrm{VL}$ & 0.06 & 0.04 & 0.03 & 0.05 & 0.03 \\
\hline E22 & $\mathrm{W}_{\mathrm{C} 26}=\mathrm{VH}, \mathrm{W}_{\mathrm{C}, \mathrm{i}, \mathrm{i} 26}=\mathrm{VL}$ & 0.07 & 0.05 & 0.04 & 0.06 & 0.03 \\
\hline E23 & $\mathrm{W}_{\mathrm{C} 27}=\mathrm{VH}, \mathrm{W}_{\mathrm{Ci}, \mathrm{i} i 27}=\mathrm{VL}$ & 0.07 & 0.05 & 0.04 & 0.06 & 0.03 \\
\hline E24 & $\mathrm{W}_{\mathrm{C} 29}=\mathrm{VH}, \mathrm{W}_{\mathrm{Ci}, \mathrm{i}+29}=\mathrm{VL}$ & 0.07 & 0.05 & 0.04 & 0.06 & 0.03 \\
\hline E25 & $\mathrm{W}_{\mathrm{C} 31}=\mathrm{VH}, \mathrm{W}_{\mathrm{Ci}, \mathrm{i} \neq 31}=\mathrm{VL}$ & 0.07 & 0.05 & 0.04 & 0.06 & 0.03 \\
\hline E26 & $\mathrm{W}_{\mathrm{C} 32}=\mathrm{VH}, \mathrm{W}_{\mathrm{Ci}, \mathrm{i} \neq 32}=\mathrm{VL}$ & 0.05 & 0.04 & 0.04 & 0.05 & 0.02 \\
\hline
\end{tabular}

Table VI shows that out of 26 experiments, the alternative P1 (i.e. Shopify) has the highest score in 21 experiments. In other five experiments, P4 (i.e. $3 \mathrm{dCart}$ ) has a similar score to $\mathrm{P} 1$. Therefore, Shopify is recommended as the most sustainable alternative.

\section{V.CONCLUSION AND FUTURE WORK}

Web accessibility related to cloud computing is more concerned at the application level where a human interacts with an application via a user interface, such as websites as a software-as-a-service. We evaluated the web accessibility of SaaS e-commerce platform websites using the cloud accessibility taxonomy framework [4] for people with disabilities. We conducted an expert evaluation using Fuzzy TOPSIS (Technique for Order of Preference by Similarity to Ideal Solution). Sensitivity analysis is also conducted to see the importance of criteria weights in selecting the best alternative among the SaaS e-commerce platforms. Finally, the results show Shopify is ranked high followed by 3dCart, BigCommerce, Volusion, and WooCommerce. This means Shopify meets a high number of web accessibility features from the proposed cloud accessibility framework.

The use of accessibility APIs and the Global Public Inclusive Infrastructure (GPII) is the cloud-based approaches to accessibility. However, the current web content accessibility guidelines (WCAG 2.0) is also applicable to cloud-based SaaS websites. Methods for evaluating web accessibility include online accessibility evaluation tools and expert evaluation. Thus, the SaaS platform selected in this study may report different web accessibility errors by applying WCAG 2.0.

\section{REFERENCES}

[1] B. Wang and J. Tang, "The Analysis of Application of Cloud Computing in E-Commerce," in 2016 International Conference on Information System and Artificial Intelligence (ISAI), 2016, pp. 148-151.

[2] S. H. Kim, S. Y. Jang, and K. H. Yang, "Analysis of the Determinants of Software-as-a-Service Adoption in Small Businesses: Risks, Benefits, and Organizational and Environmental Factors," Journal of Small Business Management, vol. 55, pp. 303-325, 2017.

[3] P. Mell and T. Grance, "The NIST Definition of Cloud Computing," National Institute of Standards and Technology: U.S. Department of Commerce, 2011.

[4] R. B. Bohn and J. Tobias, "Cloud Computing and Accessibility Considerations," N. I. o. S. a. Technology, Ed., ed: NIST Special Publication 500-317 (DRAFT), 2016.

[5] A. Benlian, M. Koufaris, and T. Hess, "Service Quality in Software-as-a-Service: Developing the SaaS-Qual Measure and Examining Its Role in Usage Continuance," Journal of Management Information Systems, vol. 28, pp. 85-126, 2011

[6] W.-W. Wu, L. W. Lan, and Y.-T. Lee, "Exploring decisive factors affecting an organization's SaaS adoption: A case study," International Journal of Information Management, vol. 31, pp. 556-563, 2011.

[7] W.-W. Wu, "Mining significant factors affecting the adoption of SaaS using the rough set approach," Journal of Systems and Software, vol. 84, pp. 435-441, 2011

[8] J. Du, J. Lu, D. Wu, H. Li, and J. Li, "User acceptance of software as a service: Evidence from customers of China's leading e-commerce company, Alibaba," Journal of Systems and Software, vol. 86, pp. 2034-2044, 2013

[9] C. Lewis and N. Ward, "Opportunities in Cloud Computing for People with Cognitive Disabilities: Designer and User Perspective," Users Diversity: 6th International Conference, Orlando, FL, USA, July 9-14, 2011, Proceedings, Part II, C. 


\section{Accepted Manuscript: 2018 IEEE International Conference on Fuzzy Systems (FUZZ-IEEE 2018)}

Stephanidis, Ed., ed Berlin, Heidelberg: Springer Berlin Heidelberg, 2011, pp. 326-331.

[10] A. Milić, K. Simić, and M. Milutinović, "Cloud Computing Environment for e-Learning Services for Students with Disabilities," in Continued Rise of the Cloud: Advances and Trends in Cloud Computing, Z. Mahmood, Ed., ed London: Springer London, 2014, pp. 363-381.

[11] D. Mulfari, A. Celesti, M. Villari, and A. Puliafito, "Using Virtualization and Guacamole/VNC to Provide Adaptive User Interfaces to Disabled People in Cloud Computing," presented at the Proceedings of the 2013 IEEE 10th International Conference on Ubiquitous Intelligence \& Computing and 2013 IEEE 10th International Conference on Autonomic \& Trusted Computing, 2013.

[12] G. A. D. Lucca, A. R. Fasolino, and P. Tramontana, "Web site accessibility: identifying and fixing accessibility problems in client page code," in Seventh IEEE International Symposium on Web Site Evolution, 2005, pp. 71-78.

[13] K. Wille, R. R. Dumke, and C. Wille, "Measuring the Accessability Based on Web Content Accessibility Guidelines," in 2016 Joint Conference of the International Workshop on Software Measurement and the International Conference on Software Process and Product Measurement (IWSMMENSURA), 2016, pp. 164-169.

[14] D. Zhonghua and H. Erfeng, "Analysis of SaaS-Based ECommerce Platform," in 2010 International Conference on EBusiness and E-Government, 2010, pp. 9-12.

[15] F. Shaikh and D. Patil, "Multi-tenant e-commerce based on SaaS model to minimize IT costs," in 2014 International Conference on Advances in Engineering \& Technology Research (ICAETR 2014), 2014, pp. 1-4.

[16] A. M. Talib and F. O. Alomary, "Cloud Computing Based ECommerce as a Service Model: Impacts and Recommendations," in Proceedings of the International Conference on Internet of things and Cloud Computing, 2016, p. 27.

[17] W. Hussain, F. K. Hussain, O. K. Hussain, E. Damiani, and E. Chang, "Formulating and managing viable SLAs in cloud computing from a small to medium service provider's viewpoint: A state-of-the-art review," Information Systems, vol. 71, pp. 240259, 2017.

[18] A. Alghamdi, W. Hussain, A. Alharthi, and A. B. Almusheqah, "The Need of an Optimal QoS Repository and Assessment Framework in Forming a Trusted Relationship in Cloud: A Systematic Review," in 2017 IEEE 14th International Conference on e-Business Engineering (ICEBE), 2017.

[19] W. Hussain, F. K. Hussain, O. Hussain, and E. Chang, "Profilebased viable service level agreement (SLA) violation prediction model in the cloud," in P2P, Parallel, Grid, Cloud and Internet Computing (3PGCIC), 2015 10th International Conference on, 2015, pp. 268-272.

[20] M. A. Beltt, R. P. Douglas, C. Martin, M. Mechmann, and M. E. Borchert, "SLA Compliance Determination with Real User Monitoring," ed: Google Patents, 2016.

[21] M. Tang, X. Dai, J. Liu, and J. Chen, "Towards a trust evaluation middleware for cloud service selection," Future Generation Computer Systems, vol. 74, pp. 302-312, 2017.

[22] O. Sohaib and M. Naderpour, "Decision making on adoption of cloud computing in e-commerce using fuzzy TOPSIS," in 2017 IEEE International Conference on Fuzzy Systems (FUZZ-IEEE), 2017, pp. 1-6.

[23] W3C Introduction to Web Accessibility. Available: https://www.w3.org/WAI/intro/accessibility.php
[24] W3C. (2008, December 2017). Web Content Accessibility Guidelines $\quad$ (WCAG) 2.0. Available: http://www.w3.org/TR/WCAG20/

[25] O. Sohaib and K. Kang, "Assessing Web Content Accessibility of E-Commerce Websites for People with Disabilities," in International Conference on Information Systems Development, Katowice-Poland, 2017, pp. 1-6.

[26] O. Sohaib and K. Kang, "E-Commerce Web Accessibility for People with Disabilities," in Complexity in Information Systems Development, J. Goluchowski, Ed., ed: Springer, 2017, pp. 87100.

[27] J. Lu, G. Zhang, D. Ruan, and F. Wu, Multi-Objective Group Decision Making : Methods, Software and Applications with Fuzzy Set Techniques: Imperial College Press, 2007.

[28] A. Mardani, A. Jusoh, K. Md Nor, Z. Khalifah, N. Zakwan, and A. Valipour, "Multiple criteria decision-making techniques and their applications - a review of the literature from 2000 to 2014," Economic Research-Ekonomska Istraživanja, vol. 28, pp. 516$571,2015$.

[29] C.-L. Hwang and K. Yoon, Multiple Attribute Decision Making Methods and Applications A State-of-the-Art Survey, 1981.

[30] M. Behzadian, S. Khanmohammadi Otaghsara, M. Yazdani, and J. Ignatius, "A state-of the-art survey of TOPSIS applications," Expert Systems with Applications, vol. 39, pp. 13051-13069, 2012.

[31] S.-J. Chen and C.-L. Hwang, "Fuzzy multiple attribute decision making methods," in Fuzzy multiple attribute decision making, ed: Springer, 1992, pp. 289-486.

[32] A. Awasthi, S. S. Chuhan, H. Omrani, "Application of fuzzy TOPSIS in evaluating sustainable transportation systems," Expert System with Application, vol. 38, issue 10, pp.1227012280, 2011. 